\title{
Reference Service in the Divisional Plan Library: Some Tentative Questions
}

By CLIFTON BROCK

$S^{\prime}$ AMUel Rothstein, in his study entitled The Development of Reference Services, has provided an admirable survey of reference services as they have evolved in American public, special, and academic libraries. Rothstein documents fully the impression that the quality of reference service in special libraries has been far better than in the other two types of libraries. He notes, for instance, that "university libraries generally lagged far behind in the development of reference service. Most university libraries were only beginning upon the primary specialization by function when other types of research libraries were already well on their way toward secondary specialization by subject." 1 Rothstein notes further that university libraries lagged most noticeably in their service to faculty members and graduate students. He found the greatest deficiency in the usual practice of reference service in general research libraries to be:

the lack of special provisions for scholars. Serving groups of readers whose needs were exceedingly diverse, reference departments naturally tended to subordinate service to the research group in the interest of the far more numerous general readers. ${ }^{2}$

There are obvious reasons for the difference in quality of reference service as provided in special research libraries and in general research libraries, such as a university library. Reference service in the special library, if not the be-all and

1 Samuel Rothstein, The Development of Reference Services through Academic Traditions, Public Librar Practice and Special Librarianship (ACRL Monograph. No. 14; [Chicago: Association of College and Reference Libraries, 1955]), p. 51.

I Ibid., p. 87.
Mr. Brock is Librarian, School of Business Administration, University of North Carolina.

end-all of the whole library operation, is certainly its most important end product. High-quality reference service is facilitated by the fact that the special librarian has a specific clientele, and usually within a specialized field of knowledge.

In university libraries, however, this situation is almost exactly reversed. The goals of a university library are as varied as the goals of the institution it serves, and the word "university," of course, connotes a wide range indeed. Reference service is only one of many functions of a university library, and-judging by the proportion of library budgets directly or indirectly applied to it-far from the most important function.

Also, in addition to the presence of other and perhaps competing functions, the university library has a number of widely differing clienteles, ranging from the well-known freshman who starts for the front door when he is told to find the main entry to the professor engaged in some esoteric field of knowledge. Caught between the numerous if simple demands of an evergrowing crop of freshmen on the one hand and the fewer but often far from simple demands of research professors on the other, and with various gradations in between, university reference librarians should be forgiven if they sometimes reflect on Churchill's famous statement and wonder if ever so few have tried to do so much for so many. 
Despite the evident truth of Rothstein's contention, and regardless of competing commitments, university librarians have made at least three distinct efforts to provide better service-and as part of this better reference service-to their clienteles. These efforts, taken in the order of their appearance, have been:

1. The development of branch or departmental libraries in special subject fields.

2. A brief, experimental program at two universities setting up what were known as "research librarianships."

3. The application of the divisional plan of organization to university libraries.

The first two efforts in this list have been covered fully by Rothstein, and will be passed over lightly here. Perhaps it is not too much of a simplification to say that, for most university libraries, neither of these efforts was feasible because of interacting financial and personnel considerations.

Departmental libraries, of course, still flourish today in many larger universities, and departmental libraries in the natural and physical sciences appear to be a permanent fixture on all but the smallest university campuses. Rothstein, and many others, have been skeptical about the quality of reference service provided in departmental libraries, which were too often faculty enclaves presided over by a departmental secretary. In any case, departmental libraries in subject areas of the humanities and social sciences have been and are rapidly disappearing in all but the largest universities. This development is due in part to changes in teaching methods, changes in the content of subject fields, rising costs in the acquisition, cataloging, and housing of collections, and the difficulty of recruiting and expense of paying a large number of special librarians.

The second of the developments listed above, that of "research librarianships," was tried out at Cornell and the University of Pennsylvania in the late 1930's.
One "research librarian" was placed at each of these two institutions. These men were to provide research and reference assistance to scholars in the humanities and social sciences, much as laboratory assistants served the natural scientists, and their time was exclusively at the disposal of faculty members in these two areas.

This experiment was carried on for about three years, under a grant from the Carnegie Corporation. Rothstein says that, "to judge from the official evaluation made by the faculty members and the library directors in charge, the whole experiment was an almost unqualified success." Then he adds, "Yet strangely enough, it had little effect. Most discouraging of all was the fact that the whole venture attracted surprisingly little emulation from other universities."3

In his post-mortem on the "research librarianship" experiment, Rothstein traced its demise to several factors:

1. The timing was bad. The depression decade was no time for expansion of services.

2. The personnel problems involved were insurmountable. The two research librarians averaged two months on the projects they undertook. No university library could afford to pay for such a low output.

3. An administrative problem was involved, in that the research librarians were largely independent of the library administration. Rothstein also infers that some jealousy existed among the general reference librarians, who saw these somewhat exotic creatures encroaching on their domain.

4. Finally, the experiment ignored the whole principle of subject specialization. Rothstein says that "both research librarians acted as complete generalists, assisting in inquiries concerning subjects ranging from medieval literature to economics." The inordinate amount of time taken on various projects, he

3 Ibid., p. 95. 
feels, was due largely to the librarians' initial unfamiliarity with the subject matter.4

This brings us to a logical point for consideration of the third effort mentioned, that of the application of the subject divisional plan of organization to academic libraries. The other two efforts have been traced fully by Rothstein, and the discussion of them here has been based largely on his study. Rothstein ended his survey of the development of reference services with 1940 , however, just as the divisional plan was receiving its first trial in university libraries.

The subject divisional plan-or variations of it-now has been in use for twenty years, and has spread from its inception at Colorado, Brown, and Nebraska to numerous other libraries. However, thorough search of the literature reveals little material which makes any attempt to evaluate the divisional plan from the point of view of reference service. There are some meaty discussions of its effects upon library building and planning, location of collections, library administration, and student access to and use of materials. And, lately, there have been evaluations of various moves to integrate the divisional system with library acquisition and cataloging. But whatever consideration given to the effects of the divisional plan on university library reference service appears to be little more than assertions that it should improve the quality of that service, and these are usually couched in terms of "ideal possibilities" or expressed in words of pious hope. All this is meant only as a warning that most of what follows has little evidential basis, and is directed more toward posing questions than providing answers.

In studying the origin and early development of the divisional plan in academic libraries, one can see several fac-

I Ibid., p. 96-97. tors apparently at work. Without going into other motivating factors-such as the expense of maintaining departmental libraries, changes in methods of teaching, a growing interdisciplinary approach to knowledge, especially in the social sciences-one can say that concern for reference service was certainly a major factor behind adoption of the divisional plan.

This concern is evident in all the early literature on the plan. In sum. mary, it boiled down to a growing realization on the part of library administrators that, in an era of great expansion of the frontiers of knowledge, accompanied by its increasing fragmentation and specialization, the general reference department could no longer be all things to all men. Frank Lundy, perhaps the most vocal proponent of the divisional plan, paints a satirical portrait of this concept of the reference librarian as a Renaissance man:

You are familiar with the content of the traditional reference room or main reading room, as it was sometimes called. The reference sets were there; the major encyclopedias in several languages, the dictionaries, World Almanac and other such handbooks, the indices and the prearranged bibliographies. In the center of the room was the reference desk, where 'the best' of all these reference books had been brought together within arm's length. And there sat the reference librarian, the modern Lord Bacon, with all the world's knowledge under control.5

Concern for reference service, then, was at least one of the major factors behind the transition from a functional form of organization to a subject divisional plan, in which pertinent library materials, whatever their form, were brought together in one area-usually in divisions labeled "Humanities," "Social Sciences," and "Science and Tech-

\footnotetext{
5 Frank A. Lundy, The Divisional Plan Library (Aspects of Librarianship, No. 18 [Kent, Ohio: Department of Library Science, Kent State University n.d.]).
} 
nology"-and placed under the supervision of librarians possessing competent knowledge of subject matter as well as of library operations.

Arthur McAnally has said that "the idea of organizing centralized university library service along divisional lines ... has been the greatest advance in university library service in the last twenty years. ..."6 But in another place McAnally has also said, "It should be noted that this organization [the centralized subject divisional plan] appears to have many advantages, but has never been evaluated." 7

Despite the lack of really substantive evaluations, it would appear that, in terms of building planning, location of collections, and facility of use, the divisional plan has been a major improvement over the earlier "forms and processes" functional plan library. The author has worked in both types of libraries and believes, for what it is worth, that with respect to reference service also, the divisional system is an improvement over the impossibly utopian idea that reference librarians can, so to speak, "cover the waterfront" of modern knowledge, a waterfront which today extends into areas Lord Bacon never dreamed of.

But the main concern here is with reference service, and especially reference service to the more scholarly segments of the university community. It is in this area that some questions may be raised about whether the divisional plan has accomplished in practice quite what it was supposed to do in theory.

First of all, from the beginning, the real key to improving reference service under the divisional plan was the staffing of the divisions by subject specialists. Ralph Ellsworth, in an early article outlining the new system at Colorado, felt

\footnotetext{
- Arthur M. McAnally. "Co-ordinating the Denartmental Library System," Library Quarterly, XXI (1951), 113 .

7 Arthur M. McAnally, "Organization of College and University Libraries," Library Trends. I (1952), 29.
}

that the minimum qualifications for divisional librarians should be "the graduate library degree, and at least a master's degree in one of the subject fields" covered by the division. ${ }^{8}$ Lundy, when urging that the University of Notre Dame change to a divisional plan library, said that the typical division should be staffed with "two or three professional librarians, each with training equivalent to the master's degree in an appropriate subject field as well as in librarianship at the same level." 9

The theory behind this was that reference librarians so trained, and working within a more restricted range than traditional reference librarians, would be able to provide better reference service. Presumably, they would also be able to meet the university faculty on grounds approaching intellectual equality and could render them valuable assistance in their research. The theory seems logical enough. But obviously, its effectiveness in practice would depend upon whether or not the divisions were actually staffed in the manner indicated.

Curiously enough, no one appears to have published a study of the actual staffing of divisions. In an attempt to get at some approximation of practice in this area, a survey was made of the catalogs of thirteen universities whose libraries use the divisional plan. In most cases, the personnel listings in these catalogs were not organized so that the library staff members and their degree qualifications could be abstracted. In five catalogs, however, the library staff was listed separately from the university faculty, and the listings showed positions held-Social Sciences Librarian, Assistant Humanities Librarian, etc.-and degrees held. Of the fifty divisional librarians identified, only fourteen, or 28 per cent, held graduate degrees in library

\footnotetext{
${ }^{8}$ Ralph E. Ellsworth, "The Training of Divisional Reading Room Librarians," CRL, VI (1944), 5.

${ }^{\circ}$ Louis R. Wilson and Frank A. Lundy, Survey of the Library of the University of Notre Dame, (Chicago: American Library Association, 1952), p. 73.
} 
science and in a subject field, the minimum qualifications set by Ellsworth, Lundy, and others.

It is evident that this was a most unscientifically constructed sample, one which would be derided by any selfrespecting social scientist. But, if the results are even a rough approximation of reality, practice lags far behind theory in the staffing of divisions.

Even in situations where divisions may be staffed according to theory, moreover, questions still might be raised about the quality of reference service. As the divisional plan was set out in theory, and as it has evolved in practice, the divisional librarians, while specialists in subject matter, are generalists with respect to library operations. In other words, depending upon the functional organization within a particular division, they may be circulation librarians, reserve book librarians, and periodical and serial librarians, as well as reference librarians. This raises the possibility that they could become so absorbed with routine duties, or with administrative supervision of these duties, that they might not have adequate time to devote to reference service.

In 1939, Ellsworth observed that the divisional plan should operate so as to make possible the separation of profession from clerical duties:

Under the traditional library plan it is difficult to make use of subject librarians without burdening them with clerical tasks. The divisional librarians ought to be subject specialists as well as technicians, because they will have little clerical work to do and they can devote their energies to interpreting books and to advanced bibliographic research. 10

In 1958, however, upon returning to Colorado, Ellsworth estimated that "the divisional librarians were spending 60

\footnotetext{
10 Discussion by Ellsworth in M. Llewellyn Raney, "Essentials of a University Library Building-II," CRL, I (1939), 56 .
}

to 75 per cent of their time on clerical aspects of reserve and circulation."11

Under these or similar conditions, it is logical to expect that reference or research service to faculty members and graduate students would suffer most, since this is likely to be high-quality service demanding much time and ingenuity on the part of the librarian. It should be emphasized that there is little firm evidence that such a development is characteristic of the divisional plan. Much depends upon such factors as the size of the library, the size of the student body, the service load, and the organization and staffing of particular divisions. For lack of critical studies, no categorical answer is available. It can be said, however, that the possibility of such a development is present in the divisional plan by virtue of its functional generality.

Furthermore, in recent experiments in which the functions of book selection and cataloging have been assumed by the divisional staff, an outsider might wonder at least if such a possibility has not been realized. First at Nebraska, and more recently at Washington State, this extension of the divisional concept into acquisition and cataloging has been made. In one report on this new development, Lundy has stressed the logic of the extension. With subject specialists available in the divisions, the first extension came by making use of their subject knowledge in book selection. The staff, says Lundy:

thus acquires a preliminary acquaintance with the new books even before they arrive. After their arrival, it seems illogical to introduce a new staff to classify and catalog these same books. And so we have assigned the divisional staffs to continue their good work by cataloging and classifying all the books they have already selected for addition to the library. On the basis of this thorough bibliographical and actual acquaintance with their many new ma-

${ }^{11}$ Letter from Ellsworth to author, October 3, 1960. 
terials, where would you hope to find a staff better qualified to carry through with all the reference and advisory functions of the public service divisions? 12

The logic of this is extremely persuasive, and Lundy does not overlook its application to reference service. It is doubtful if anyone will quarrel with the contention that a reference librarian who is also a cataloger will be a better reference librarian. But, again, the possibility is present that the addition of other time-consuming functions could actually detract from reference service. Everything would depend upon staffing. If enough divisional librarians were employed to absorb the added load, this new development would certainly lead to better reference service.

From the literature, it was not possible to determine precisely what staffing changes were made to meet this situation at Nebraska and Washington State. At Nebraska, apparently there were sufficient junior divisional librarians already available to absorb the bulk of the cataloging function. In 1955, at Washington State, there were eight professional librarians in the social sciences division, six in science, and five in humanities. Each of these librarians apparently devoted approximately half time to cataloging and acquisitions work. ${ }^{13}$ This was roughly double the number of professionals usually assigned to conventional subject divisions. In 1959, however, only three professionals were employed in the humanities division, and apparently with substantially the same work load as before. ${ }^{14}$

Theoretically, the dual assignment also provides an opportunity to meet one of the major criticisms of the divisional plan. This is the objection that placing two or three specialists in particular sub-

\footnotetext{
12 Lundy, op. cit. p. 7-8.

13 Clarence Gorchels, "Making Subject Specialists Available for Service,"' $C R L$, XVI (1955), 348.

14 Hanna E. Krueger, "Acquisitions and Cataloging; an Integral Part of Reader Services," Library Resources and Technical Services, III (1959), 195.
}

jects in divisions that actually encompass six or seven subjects is not adequate. The dual assignment would meet this objection if two or three more subject specialists could be placed in each division. Practically, the lack of adequate financial resources and the scarcity of subject specialists operate against this. If not enough subject specialists can be found to staff conventional subject divisions, where are the others to come from?

Another point which cannot be overlooked is that this extension was made primarily with cataloging problems in mind. This is abundantly clear from Lundy's and other articles on the subject. One suspects, in fact, that the real motivating force behind this development was the scarcity of catalogers. Lundy has written one extensive report on the cataloging aspects of the dual assignment ${ }^{15}$ and has promised another on the book selection aspects. ${ }^{16}$ But so far, apparently no real evaluation has been made from the reference viewpoint. The reason for this may well be the difficulty of applying meaningful quantitative measurements to such an elusive service as reference. But the fact that such measurements are difficult could well lead to an unobserved loss in the quality of reference service.

These tentative questions are not meant to imply that the dual assignment is a bad move on the part of university libraries. It may well be a good move from the point of view of library administration as a whole, possibly from the reference viewpoint as well. But the evidence is not yet in, at least from the reference angle. The dual assignment is, however, an excellent illustration of the point made above, that the numerous functions inherent in a university library pose problems of reference service which may not be so acute in special li-

\footnotetext{
15 Frank A. Lundy and others, "The Dual Assignment: Cataloging and Reference: A Four-Year Review of Cataloging in the Divisional Plan," Library Resources and Technical Services, III (1959), 167-83.

10 Frank A. Lundy. "More on the Dual Assignment," Library Journal, LXXXV (1960), 2994.
} 
braries, and which could have a deleterious effect on the quality and quantity of that service.

Finally, brief consideration should be given to subject divisional reference service from the point of view of the scholars themselves. Rothstein notes that it used to be argued that scholars, especially in the humanities and social sciences, did not need or want reference or research assistance from librarians. These men were deemed competent to do their own work, and furthermore, wanted to do it. Rothstein calls this the "conservative theory" of reference service, ${ }^{17}$ and it must be a strange theory indeed to a special librarian. It is still heard today among some university librarians, however, and certainly there are humanists and social scientists today who would consider extensive assistance to be in the same category as ghost-writing. It now appears that such hardy specimens are fast disappearing, and primarily for two reasons.

First, along with the growing trend toward interdisciplinary research, there is also increasing specialization or fragmentation of knowledge. An illustration may serve to make this point. Not long ago a political scientist came to a divisional librarian and confessed that he needed help. This man was a specialist in political philosophy; he knew his Plato and Aristotle backwards and forwards. But he had become a consultant in a research project which forced him to acquire some background in the numerous political behavior studies of the last ten or fifteen years, studies which themselves are based heavily on sociological and psychological data. He said he could get at this material himself, but thought the librarian might be able to speed up the process; and anyway, he could use something which would translate all that psychological and sociological jargon into plain English. This man could have gone to his colleagues in po-

\footnotetext{
${ }^{17}$ Rothstein, op. cit., p. $42-44$.
}

litical science and the other departments, of course, but he came to the library for help and expected to get it. His own subject had become so specialized that he had been unable to keep up except in his own circumscribed area.

The second impetus towards increasing demands upon the library for research assistance is the simple fact that, even when scholars are fully competent to do their own research work, many are no longer doing it. They send research assistants to the library to collect data, and too often the research assistants lack the necessary competence. This development is much less evident in the humanities, but in the last twenty years the social sciences have become about as "foundationalized" as the natural sciences. It is indeed a poor professor today who cannot command foundation or government research grants to finance his work and thus acquire one or more research assistants.

This development can be readily observed at the University of North Carolina. At Chapel Hill there is an Institute for Research in Social Science, composed of professors from the various social science departments engaged part-time or full-time on research projects financed by the Institute from foundation or other grants. The Institute is staffed by 48 research professors or associate research professors. It also employs $\mathbf{5 4}$ graduate students as research assistants assigned to the various members of the Institute. In addition to this, the various social science departments themselves also employ other assistants who serve as research help to faculty members who are not members of the Institute. The department of political science, for instance, employs six research assistants. The school of business administration and economics also employs six research assistants, and so on.

These figures have a good deal of meaning for the library's business administration and social sciences division. 
Again, perhaps an illustration will help. There is a professor of business administration at Chapel Hill whom I have seen in the library exactly once within the last year. Few weeks have passed, however, when his research assistant has not been in several times. This assistant, unfortunately, is one who has to be taken by the hand if he is to find Census of Business. A few weeks ago this professor telephoned to say that his assistant had graduated at the end of the summer, and he supposed this would not make us too unhappy. We admitted that we were not going to cry about it. The professor said he had never seen such a one in his life, but now he had a new assistant who seemed a lot sharper, and could we take a couple of hours to give him some instruction on the materials he would need to use? The professor said he would like to get over to the library and do the work himself, but heavy teaching and research loads had him pinned down to the classroom and office. Fortunately, most research assistants are not like this one. But even at their best, and with the best of intentions, they cannot do the independent library research which the professor himself could do.

Thus, because of these two developments, as well as others, the old conservative theory of reference aid to scholars, which may have worked well enough twenty years ago, just no longer applies. These developments, of course, pose problems for any reference service, whether it is organized along traditional lines or along subject divisional lines. In theory, the divisional was a major advance over the traditional plan, and it appears to meet the problems outlined here more adequately than traditional reference service. But whether the divisional plan, as it has evolved in practice, meets them as they need to be met today is an open issue.

In a sense, the divisional plan can be viewed as a useful compromise for many universities between the two attempts to provide better service discussed briefly above. Lundy once wrote of the divisional plan as being a "half-way" solution to the dilemma posed by the financial inability to maintain a score of departmental libraries in the humanities and social sciences and the inadequacy of traditional reference departments when faced with the impossible range and depth of modern knowledge. ${ }^{18}$ Thus, from the beginning, the divisional plan, in theory, was seen as only a half-way solution. If the doubts aired here about the plan in practice were to prove wellfounded, it would appear that today it may no longer be even a half-way house to the model of reference and research assistance for university librarians found in certain special libraries.

These tentative criticisms, aimed here at reference service in divisional plan libraries, might apply with equal or greater force to traditional reference service. None of the questions raised, or the ultimate question of the quality of reference service in general, regardless of specific organizational patterns, can be answered until scientific techniques of evaluation are devised. Such techniques do not now exist, and many members of the profession seem to feel that they cannot be developed. In view of the tremendous advances in quantitative methodology made in recent years by the social scientists, such an outlook seems a premature expression of defeat. One suspects that in some instances it might be a defense mechanism on the part of those who do not wish their work investigated. Possibly librarians, and especially reference librarians, have found an easy refuge in the contention that their work is too "intangible," too "intellectual" to be weighed and measured. Increasingly, the reference function of librarians is being taken over by "documentalists" and "information specialists."

\footnotetext{
18 Wilson and Iundy, op. cit., n. 70.
} 